\title{
A Simple and Economical Root Washer
}

\section{PAUL E. NYREN, HAROLD GOETZ, AND DEAN E. WILLIAMS}

The job of separating root material from soil samples can be a difficult task when large numbers of samples are involved. Many different devices have been designed for this task, all of which have two basic components, a water supply to dissolve and remove the inorganic material and one or more screens to catch the root sample. A fine mesh screen and water under moderate pressure works well when only a few samples are involved. If many samples are to be done by one or two operators, then a more elaborate system is needed.

This problem was encountered during the summer of 1978 when two separate studies produced over 1,200 root samples. The samples had to be collected and separated during the summer season when adequate part-time help was available.

The method chosen was a modification of the one described by Lauenroth and Whitman (1971). A table was constructed out of a $1.2 \times 2.4 \mathrm{M}(4 \times 8 \mathrm{foot})$ sheet of $2-\mathrm{cm}(3 / 4 \mathrm{inch})$ exterior plywood (Fig. la). Five by ten-cm $(2 \times 4$-inch) boards were bolted to the edge of the table leaving a $30-\mathrm{cm}$ ( $1 \mathrm{foot}$ ) opening through which the water drained back into the holding tank. The table surface was then sealed against water with a thick coat of epoxy paint. Support legs were constructed out of $2.5 \times 10 \mathrm{~cm}(1 \times 4$ inch $)$ boards bolted to the corners of the table.

The root washing system consisted of 11-liter (3-gallon) galvanized buckets modified by placing a $15-\mathrm{cm}(6-i n c h)$ spout $10 \mathrm{~cm}$ (4 inches) from the upper rim (Fig. 1b-2). A hole was cut near the base of the bucket through which a short pipe nipple was inserted. To this pipe a ring lawn sprinkler was attached (Fig. 1b-4). The area around the pipe nipple was sealed by placing rubber washers on both sides. One-gallon cans were constructed to hold the soil samples by removing both the top and bottom and soldering

\footnotetext{
Authors are botanist, Dickinson Experiment Station, chairman and technician, Botany Department, North Dakota State University, Fargo, North Dakota.

Manuscript received June 23, 1979.
}

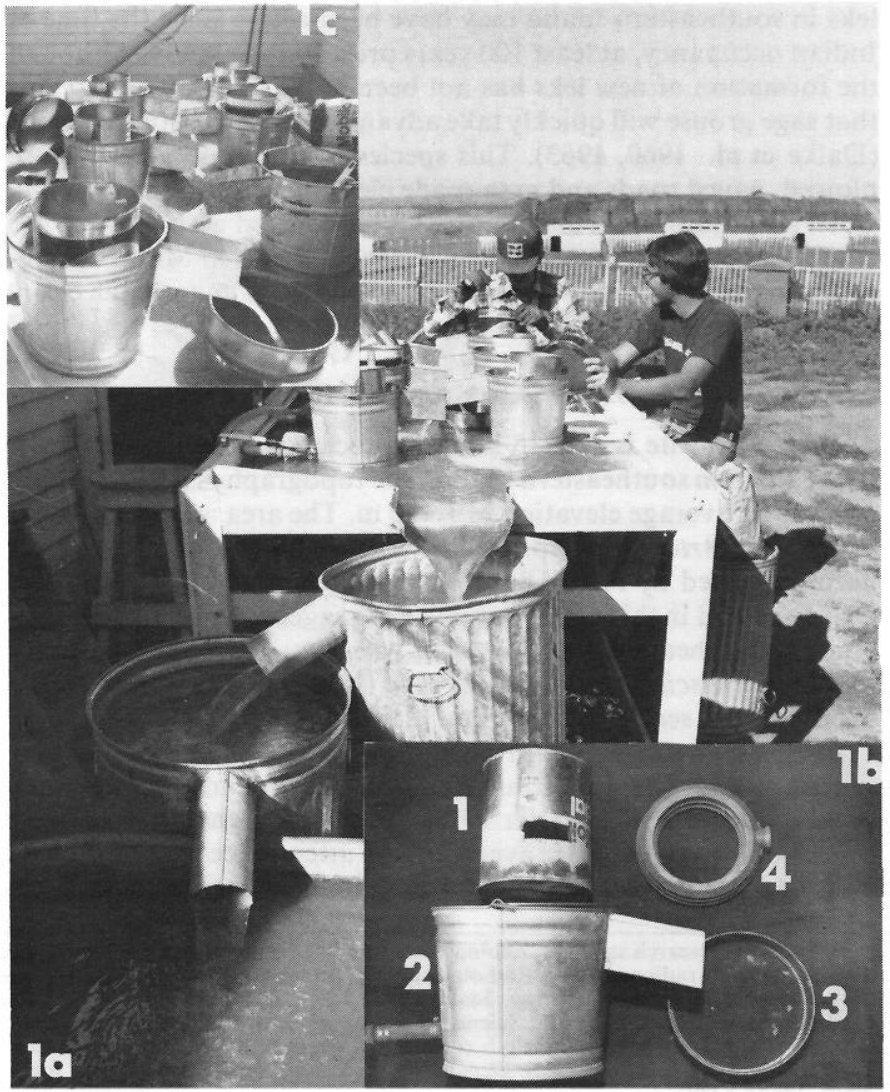

Fig. 1. (la). The root washing table constructed with a $4 \times 8$ foot sheet of 3/4-inch exterior plywood. (1b.) Close up of the modified galvanized bucket ( $1 \mathrm{~b}-2)$, gallon can with .4-mm screen attached (1b-1), ring lawn sprinkler (1b-4) and 1/2-mm laboratory sieve (Ib-3). (Ic.) Close up of root washer in operation. 
0.4-mm (40-mesh) screen to one end (Fig. 1b-1). A slot $5 \times 7.5 \mathrm{~cm}$ ( $2 \times 3$ inch) was cut in each can to correspond to the height of the spout in the bucket.

Low line pressure and a limited supply of water made it necessary to use an in line pump and recycle the water to the system. The pump supplied $2.1 \mathrm{~kg} \mathrm{~cm}^{2}(30 \mathrm{psi})$, and a hydraulic head of $18 \mathrm{M}(60$ $\mathrm{ft}$ ). A three-tank system was used to settle as much of the soil from the water as possible (Fig. la). The main reservoir was a 568-liter (150-gallon) livestock watering tank. The water exiting the wash table passed through two 113-liter (30-gallon) garbage cans to settle out as much of the soil from the water as possible, lessening the number of times the large tank had to be drained and cleaned. The intake hose to the pump was equipped with a $0.25-\mathrm{mm}(60-$ mesh) screen filter to prevent debris from entering the systems and plugging the holes in the sprinkler heads.

\section{Washing Procedure}

The root samples were collected with a Veihmeyer soil sampling tube. Nine subsamples were taken and composited into three samples per plot. The samples were separated into $15-\mathrm{cm}(6-\mathrm{inch})$ increments to $30 \mathrm{~cm}$ ( 12 inches) and 30 -cm (12-inches) increments from $30 \mathrm{~cm}$ to $122 \mathrm{~cm}$ ( 12 to 48 inches). The samples were placed into pint freezer containers and frozen until the day before they were to be separated. The root sample was placed in the 3.9-liter (1-gallon) cans and set in the bucket on top of the lawn sprinkler. The pressure of the water caused the soil material to dissolve and the roots to float to the surface. One-half $\mathrm{mm}$ ( $32 \mathrm{mesh}$ ) sieves were placed under the spout of the bucket to catch the root material (Fig. 1c). Periodically during the washing process, the cans were lifted out of the water and the small soil aggregates broken with a kitchen spatula. When the entire soil sample had been dissolved the cans were removed and the remaining undissolved sand and scoria dumped. Root material in the sieves was placed in small paper bags. In those soil samples having a moderate amount of clay content, the material trapped in the sieves had to be rewashed to dissolve the clay aggregates entirely. Those samples having a large amount of clay had to be placed in cloth bags and soaked for 8 to 12 hours in a strong water softener solution. The root samples were then placed in an oven at $66^{\circ} \mathrm{C}$ and oven dry weights recorded. Following drying the samples were ashed at $500^{\circ} \mathrm{C}$ for 4 hours and the ash weights recorded.

\section{Literature Cited}

Lauenroth, William K., and Warren C. Whitman. 1971. A rapid method for washing roots. J. Range Manage. 24:308-309. 